\title{
Catalytic Activity of a Dimeric Palladacycle of 2-Phenylaniline in Suzuki and Heck Cross-coupling Reactions
}

\author{
Kazem Karami", Zohreh Karami Moghadama, Mahboubeh Hosseini Kharata \\ Department of Chemistry, Isfahan University of Technology, Isfahan, 84156/83111, Iran \\ *Corresponding Author: karami@cc.iut.ac.ir
}

Copyright (C) 2014 Horizon Research Publishing All rights reserved.

\begin{abstract}
A dimeric NC-palladacycle of 2-phenylaniline was applied in the Suzuki reaction of aryl halides and the Heck reaction of methyl acrylate and styrene with phenylboronic acid. This palladacycle was found to be effective catalyst for the Suzuki and Heck cross-coupling reactions which could be carried out in the undried solvent under air.
\end{abstract}

Keywords NC-Palladacycle, Catalytic Activity, Suzuki Reaction, Heck Reaction, Promoter

\section{Graphical Abstract}

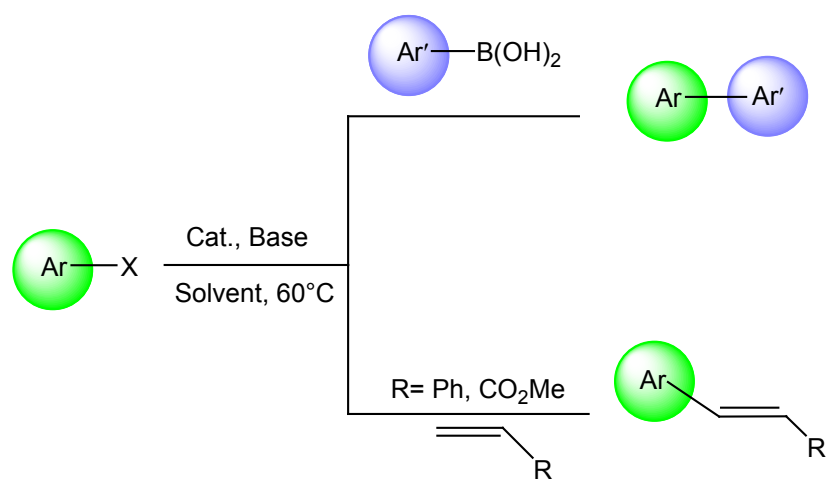

\section{Introduction}

In recent years, the Heck and Suzuki reactions have found widespread applications in synthetic organic chemistry and materials science [1-7]. Among existing catalysts for these reactions, palladacycles have played an important role due to their versatility and nontoxicity. In the majority of cases they are likely to serve as a source of highly active but unstable zero-valent palladium species [8,9].

Palladacycles are highly labile compounds, undergoing ready transformations with and without fission of palladacycle ring under rather mild conditions. Dimeric palladacycles undergo dissociation to monomeric forms in highly dilute solutions in coordinating solvents already at room temperature $[9,10]$. So, it could be tentatively assumed that at high temperatures normally used for cross-coupling reactions dimer-monomer equilibrium is fully shifted to monomeric state [9]. Furthermore, for stable palladacycles containing five-membered rings, the reductive elimination is hardly possible, while, larger palladacycles are often transient readily giving heterocycles after reductive elimination $[9,11]$.

In recent years, in addition to phosphorus containing complexes which are sensitive to moisture and air, there has been a substantial amount of research undertaken on N,C-based complexes [12,13]. These complexes are air stable, easy to obtain from a vast number of readily available nitrogen containing molecules, are generally much cheaper than phosphine-ligated palladacycles, but as or more efficient than the latter [12]. The cyclopalladated complexes with nitrogen donor atoms have been widely studied due to their novel and outstanding applications in a vast range of fields such as organic synthesis [14], insertion reaction [15], as anti-tumor drugs [16] and catalysis [17].

The use of nitrogen-based ligands have been reported to demonstrate catalytic activity in Suzuki and Heck reactions [18-29], which drew our attention to study the catalytic activity of A (Fig. 1) in homogenous media.

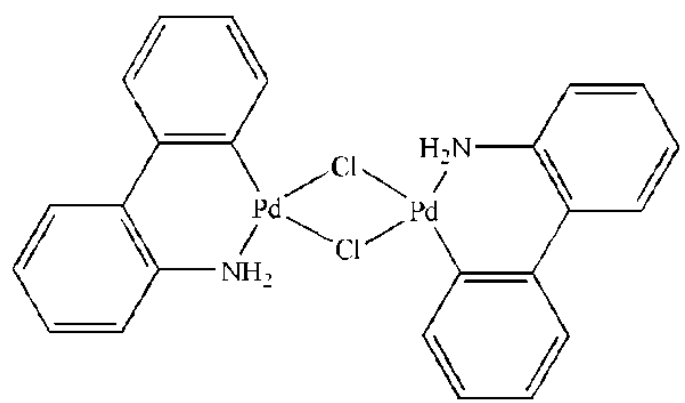

Figure 1. The dimeric NC-palladacycle A employed in Suzuki and Heck reactions 
The degradation reactions associated with P-ligands is not observed in the N-ligands, with comparable high thermal, moisture and air stability and insensitivity [13]. In view of this and as a continuation of our work on the Suzuki [30-32] and Heck [33,34] reactions, we prepared cyclopalladated compound (A) containing a 2-phenylaniline cyclopalladated unit with method reported by Albert et. al [35]. We report the efficiency of palladacycle A in Suzuki and Heck C-C cross-coupling reactions for aryl iodide, aryl bromides and chlorides.

\section{Experimental}

\subsection{Instruments and Reagents}

All chemicals and solvents were purchased from Merck and Aldrich. Conversions were monitored using an Agilent $6890 \mathrm{~N}$ gas chromatograph equipped with a capillary HP- $5^{+}$ column, based on aryl halides. The column properties were: $30 \mathrm{~m}$ long, $0.32 \mathrm{~mm}$ in inner diameter, and $0.25 \mu \mathrm{m}$ film thick.

\subsection{General Procedure for Suzuki Reaction}

A round bottom flask was charged with aryl halide $(0.5$ $\mathrm{mmol})$, phenylboronic acid $(0.75 \mathrm{mmol})$, base $(1.5 \mathrm{mmol})$, catalyst $(0.01 \mathrm{mmol})$ and solvent $(7 \mathrm{~mL})$. The mixture was heated for the time and at the temperature given in Tables 1, 2 using the base and solvent there indicated. The products were characterized by GC.

\subsection{General Procedure for Heck Reaction}

A round bottom flask was charged with aryl halide $(0.5$ $\mathrm{mmol})$, methyl acrylate or styrene $(0.75 \mathrm{mmol})$, base $(1.5$ $\mathrm{mmol})$, catalyst $(0.01 \mathrm{mmol}), \mathrm{FeCl}_{3}(0.001 \mathrm{mmol})$ and $\mathrm{MeOH}(7 \mathrm{~mL})$. The mixture was heated for the time and at the temperature given in Tables 3, 4 using the base and solvent there indicated. The products were characterized by GC.

Table 1. Suzuki coupling of bromobenzene with phenylboronic acid: Reaction conditions study

\begin{tabular}{|c|c|c|c|c|}
\hline Entry & Solvent & Base & $\begin{array}{c}\text { Temp }\left({ }^{\circ} \mathrm{C}\right) / \text { Time } \\
(\mathrm{h})\end{array}$ & $\begin{array}{c}\text { Yield }^{\mathrm{a}} \\
(\%)\end{array}$ \\
\hline 1 & Acetone & $\mathrm{KOH}$ & $60 / 1$ & 25 \\
\hline 2 & Acetone & $\mathrm{Na}_{2} \mathrm{CO}_{3}$ & $60 / 1$ & 32 \\
\hline 3 & Acetone & $\mathrm{NaOAc}$ & $60 / 1$ & Trace \\
\hline 4 & Acetone & $\mathrm{K}_{3} \mathrm{PO}_{4} .3 \mathrm{H}_{2} \mathrm{O}$ & $60 / 1$ & 8 \\
\hline 5 & DMF & $\mathrm{KOH}$ & $60 / 1$ & 48 \\
\hline 6 & $\mathrm{DMF}$ & $\mathrm{Na}_{2} \mathrm{CO}_{3}$ & $60 / 1$ & 54 \\
\hline 7 & DMF & $\mathrm{NaOAc}$ & $60 / 1$ & 20 \\
\hline 8 & DMF & $\mathrm{K}_{3} \mathrm{PO}_{4} .3 \mathrm{H}_{2} \mathrm{O}$ & $60 / 1$ & 32 \\
\hline 9 & $\mathrm{MeOH}$ & $\mathrm{KOH}$ & $60 / 1$ & 97 \\
\hline 10 & $\mathrm{MeOH}$ & $\mathrm{Na}_{2} \mathrm{CO}_{3}$ & $60 / 1$ & 99 \\
\hline 11 & $\mathrm{MeOH}$ & $\mathrm{NaOAc}$ & $60 / 1$ & 75 \\
\hline 12 & $\mathrm{MeOH}$ & $\mathrm{K}_{3} \mathrm{PO}_{4} .3 \mathrm{H}_{2} \mathrm{O}$ & $60 / 1$ & 90 \\
\hline 13 & THF & $\mathrm{KOH}$ & $70 / 1$ & Trace \\
\hline 14 & $\mathrm{THF}$ & $\mathrm{Na}_{2} \mathrm{CO}_{3}$ & $70 / 1$ & 12 \\
\hline 15 & THF & $\mathrm{NaOAc}$ & $70 / 1$ & 0 \\
\hline 16 & THF & $\mathrm{K}_{3} \mathrm{PO}_{4} .3 \mathrm{H}_{2} \mathrm{O}$ & $70 / 1$ & 0 \\
\hline 17 & $\mathrm{MeOH}$ & $\mathrm{Na}_{2} \mathrm{CO}_{3}$ & $25 / 1$ & 48 \\
\hline 18 & $\mathrm{MeOH}$ & $\mathrm{Na}_{2} \mathrm{CO}_{3}$ & $25 / 2$ & 65 \\
\hline 19 & $\mathrm{MeOH}$ & $\mathrm{Na}_{2} \mathrm{CO}_{3}$ & $50 / 1$ & 86 \\
\hline 20 & $\mathrm{MeOH}$ & $\mathrm{Na}_{2} \mathrm{CO}_{3}$ & $60 / 0.5$ & 92 \\
\hline
\end{tabular}


Table 2. Suzuki coupling of aryl halides with phenylboronic acid catalyzed by complex A

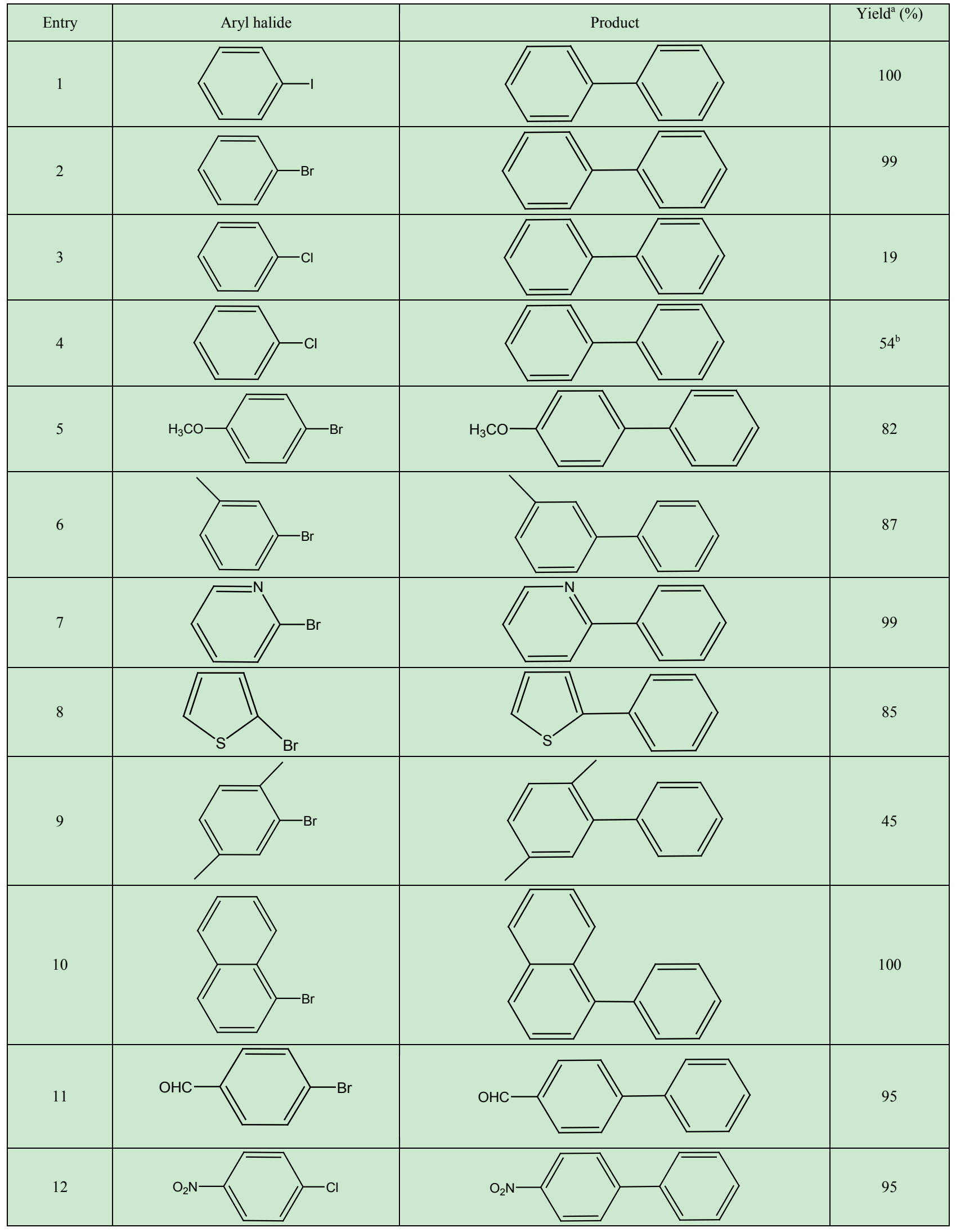


Table 3. Heck coupling of aryl halide with olefin: Reaction conditions study

\begin{tabular}{|c|c|c|c|c|c|}
\hline Entry & $\begin{array}{c}\text { Aryl } \\
\text { halide }\end{array}$ & Olefin & Base & $\begin{array}{l}\text { Time } \\
(\mathrm{h})\end{array}$ & $\begin{array}{c}\text { Yield }^{\mathrm{a}} \\
(\%)\end{array}$ \\
\hline 1 & $\mathrm{PhBr}$ & $\begin{array}{l}\text { Methyl } \\
\text { acrylate }\end{array}$ & $\mathrm{Na}_{2} \mathrm{CO}_{3}$ & 2 & 0 \\
\hline 2 & $\mathrm{PhBr}$ & $\begin{array}{l}\text { Methyl } \\
\text { acrylate }\end{array}$ & $\mathrm{Na}_{2} \mathrm{CO}_{3}$ & 8 & 0 \\
\hline 3 & $\mathrm{PhBr}$ & $\begin{array}{l}\text { Methyl } \\
\text { acrylate }\end{array}$ & $\mathrm{Na}_{2} \mathrm{CO}_{3}$ & 16 & 0 \\
\hline 4 & $\mathrm{PhBr}$ & $\begin{array}{l}\text { Methyl } \\
\text { acrylate }\end{array}$ & $\mathrm{Na}_{2} \mathrm{CO}_{3}$ & 16 & $0^{\mathrm{b}}$ \\
\hline 5 & $\mathrm{PhBr}$ & $\begin{array}{l}\text { Methyl } \\
\text { acrylate }\end{array}$ & $\mathrm{Na}_{2} \mathrm{CO}_{3}$ & 24 & 0 \\
\hline 6 & $\mathrm{PhBr}$ & $\begin{array}{l}\text { Methyl } \\
\text { acrylate }\end{array}$ & $\mathrm{Et}_{3} \mathrm{~N}$ & 24 & Trace \\
\hline 7 & $\mathrm{PhBr}$ & Styrene & $\mathrm{Et}_{3} \mathrm{~N}$ & 24 & 60 \\
\hline 8 & $\mathrm{PhI}$ & $\begin{array}{l}\text { Methyl } \\
\text { acrylate }\end{array}$ & $\mathrm{Et}_{3} \mathrm{~N}$ & 24 & 50 \\
\hline 9 & $\mathrm{PhI}$ & Styrene & $\mathrm{Et}_{3} \mathrm{~N}$ & 2 & 24 \\
\hline 10 & $\mathrm{PhI}$ & Styrene & $\mathrm{Et}_{3} \mathrm{~N}$ & 8 & 53 \\
\hline 11 & $\mathrm{PhI}$ & Styrene & $\mathrm{Et}_{3} \mathrm{~N}$ & 24 & 73 \\
\hline
\end{tabular}

Table 4. Heck coupling of aryl halides with styrene and methyl acrylate catalyzed by complex $\mathbf{A}$

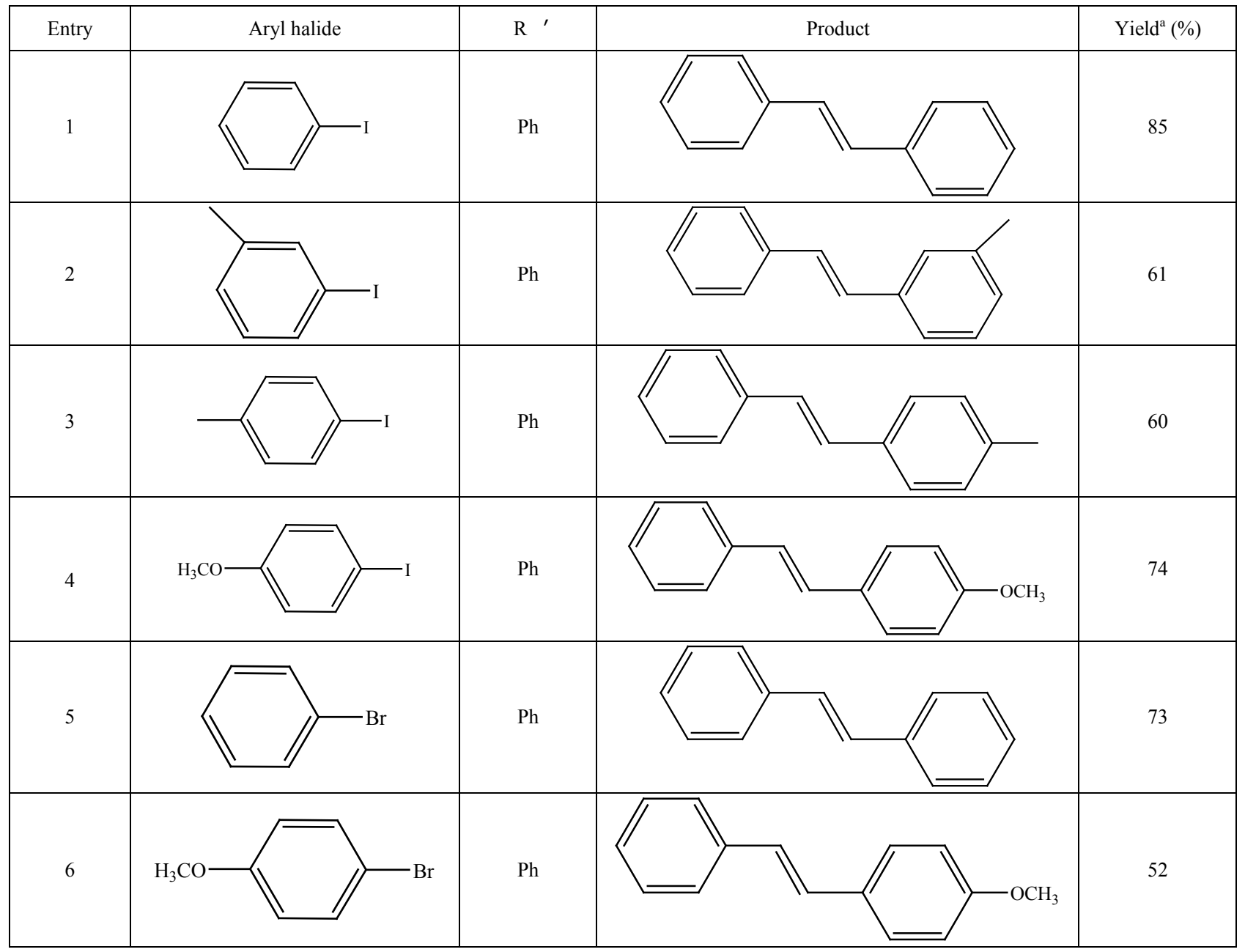




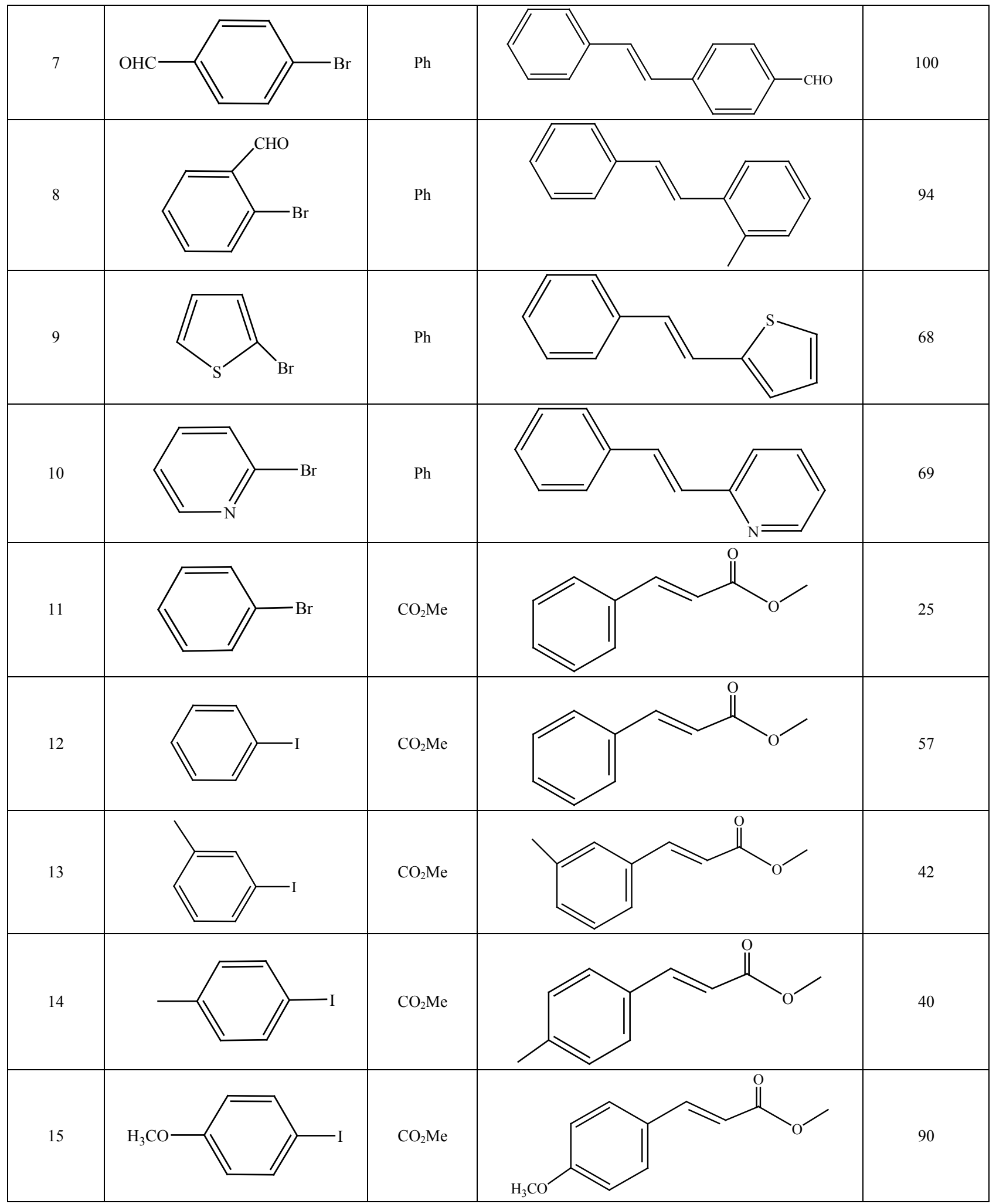




\section{Results and Discussion}

\subsection{Suzuki Cross-Coupling Reactions}

To evaluate the effectiveness of the cyclopalladated dimer $\mathbf{A}$ in the Suzuki reaction, the coupling of bromobenzene with phenylboronic acid was first chosen as a model reaction. The coupling reaction was investigated in different solvents (acetone, methanol, THF, DMF) and various bases were used $\left(\mathrm{Na}_{2} \mathrm{CO}_{3}, \mathrm{KOH}, \mathrm{NaOAc}\right.$, $\mathrm{K}_{3} \mathrm{PO}_{4} \cdot 3 \mathrm{H}_{2} \mathrm{O}$ ) at room temperature and $60^{\circ} \mathrm{C}$.

Methanol was found to be the best solvent in our screening experiments (Table 1). This may be due to the better solubility of the reagents and easier reduction of $\mathrm{Pd}(\mathrm{II})$ to $\operatorname{Pd}(0)$, and hence a facile entry to the catalytic cycle [32]. The reaction did not proceed in THF (Table 1, entry 13-16). As a base, $\mathrm{Na}_{2} \mathrm{CO}_{3}$ was the best choice (Table 1). The catalytic activity of different amount of palladacycle $\mathbf{A}$ in $\mathrm{MeOH}$ at the presence of $\mathrm{Na}_{2} \mathrm{CO}_{3}(1.5 \mathrm{mmol})$ at $60^{\circ} \mathrm{C}$ was also examined (Fig. 2). As shown in Figure 2, the yield increased with increasing the catalyst loading weight. Following optimization experiments, we found that the reaction performed in $\mathrm{MeOH}$, with $\mathrm{Na}_{2} \mathrm{CO}_{3}$ as the base in the presence of $0.01 \mathrm{mmol}$ catalyst at $60^{\circ} \mathrm{C}$ appeared to be best. After having established the optimized coupling reaction conditions, the scope of the reaction and efficiency of the palladacycle $\mathbf{A}$ was evaluated by investigating the coupling of phenylboronic acid with various aryl halides. The results were summarized in Table 2 . The influence of the halide nature was as expected in the cross-coupling reactions of iodo, bromo and chloro-benzene with phenylboronic acid (Table 2, entries 1-3). The coupling product of chloro-benzene with phenylboronic acid was obtained in a moderate yield by prolonging the reaction time (Table 2, entry 4). As summarized in Table 2, electron-deficient aryl bromide and chloride such as 4-bromobenzaldehyde and 4-chloronitrobenzene afforded excellent yields (Table 2, entries 11 and 12).

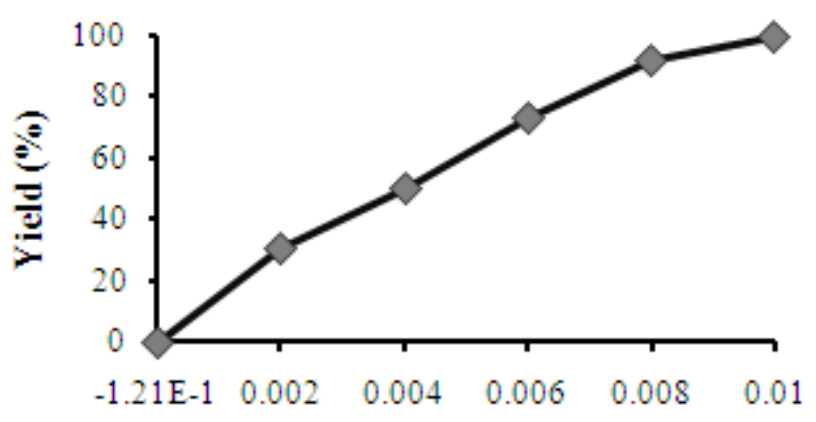

Amount of catalyst (mmol)

Figure 2. Effect of amount of catalyst (mmol) on activity of Suzuki reaction

It can be inferred that the electronic effects of the substituents on the aryl bromide and chloride had significant influence on the reaction and electron withdrawing substituents were more appropriate for the coupling [36]. Nevertheless, aryl bromides containing electron-rich groups (Table 2, entries 5 and 6) gave good yields. Palladacycle A showed excellent and good catalytic activity in the reactions of 2-bromopyridine and 2-bromothiophene with phenylboronoc acid, respectively (Table 2, entries 7 and 8 ). The coupling product of sterically hindered 2-bromo- $p$-xylene with phenylboronic acid was obtained in a moderate yield (Table 2, entry 9).

\subsection{Heck Cross-Coupling Reactions}

The catalytic activity of the palladacycle A was also studied in the Heck reaction of the aryl iodides and bromides with methyl acrylate and styrene using the optimal reaction conditions for the Suzuki coupling reactions. In the reaction of bromobenzene with methyl acrylate using catalyst $\mathbf{A}$ under the optimal Suzuki reaction conditions with a longer times (Table 3 , entries 3 and 4), no reaction occurred at $60^{\circ} \mathrm{C}$. As these conditions were not efficient for the Heck reaction of bromobenzene, another base was employed. The yield of the Heck reaction of bromobenzene with methyl acrylate in the presence of $\mathrm{Et}_{3} \mathrm{~N}$ (triethylamine) as the base was negligible, and only a trace amount of the product was obtained (Table 3, entry 6). Whereas, in the reaction of iodobenzene with methyl acrylate and styrene at different times, low to moderate yields were obtained (Table 3, entries 8-11).The optimized conditions were applied to Heck reactions between styrene and methyl acrylate with various aryl iodides and bromides (Table 4). As shown in Table 4, in the reaction of aryl iodide and bromide with styrene, good to excellent yields were obtained, respectively (Table 4, entries 1-10) and in the reaction of bromobenzene and aryl iodides with methyl acrylate low and moderate yields were obtained (Table 4, entry 11) and (Table 4, entries 11-15), respectively.

As expected, aryl halides with electron-withdrawing substituents in para positions reacted smoothly and aryl halides with electron-donating substituents were less reactive. The activated electron-deficient substrate, 4-borombenzaldehyde reacted to give high yield of the expected products (Table 4 , entry 8 ).

The use of catalytic amount of a Lewis acid $\left(\mathrm{FeCl}_{3}\right)$, as a promoter which would help labilize the halide, increased the reaction rate and the yield of the reaction [13,37].

It is possible that $\mathrm{FeCl}_{3}$ interacts with the olefin and draws away the electron density from it thus making it more reactive [37]. It is known that electron withdrawing groups on the olefin increase the rate of Heck reaction. Thus an enhancement in the activity is observed on addition of $\mathrm{FeCl}_{3}$ in the reaction of iodo and bromo benzene with methyl acrylate and styrene (Fig. 3).

\section{Conclusion}

Catalytic studies of palladacycle A revealed that it is 
efficiency active in Suzuki reactions with aryl halides. We interested to test dimer $\mathbf{A}$ in the Heck reaction with changes in the reaction conditions obtained from the Suzuki reaction. However, this palladacycle did not work as efficiently in the Heck reaction. An enhancement in the rate of palladium catalyzed Heck reactions has been achieved by using catalytic amounts of Lewis acid $\mathrm{FeCl}_{3}$ as a promoter.

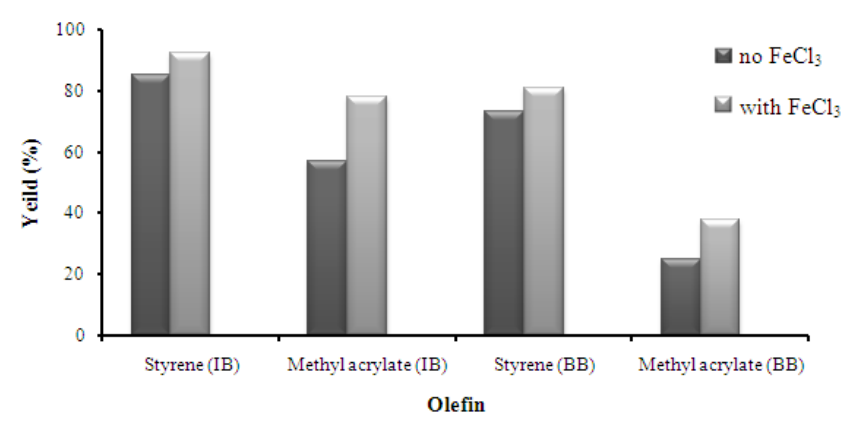

Figure 3. Influence of $\mathrm{FeCl}_{3}$ on the activity of Heck reaction

\section{Acknowledgments}

We are sincerely grateful for the financial support from the Isfahan University of Technology (IUT).

\section{REFERENCES}

[1] A.F. Littke, G.C. Fu, Angew. Chem. Int. Ed., 41 (2002) 4176.

[2] A. Suzuki, J. Organomet. Chem., 576 (1999) 147.

[3] J.F. Jensen, M. Johannsen, Org. Lett. 5 (2003) 3025.

[4] D. Badone, M. Baroni, R. Cardamone, A. Ielmini, U. Guzzi, J. Org. Chem. 62 (1997) 7170.

[5] L. Botella, C. Nájera, Angew. Chem. Int. Ed., 41 (2002) 179.

[6] Y. Shang, J. Wu, C. Fan, J. Hu, B. Lu, J. Organomet. Chem., 693 (2008) 2963.

[7] C. Cao, Y. Zhuang, J. Zhao, Y. Peng, X. Li, Z. Shi, G. Pang, Y. Shi, Inorg. Chim. Acta., 363 (2010) 3914.

[8] G.R. Newkome, W.E. Puckett, W.K. Gupta, G.E. Kiefer, Chem. Rev., 86 (1986) 451.

[9] I.P. Beletskaya, A.V. Cheprakov, J. Organomet. Chem., 689 (2004) 4055.

[10] S.G. Fiddy, J. Evans, M.A. Newton, T. Neisius, R.P. Tooze, R. Oldman, Chem. Commun., (2003) 2682.

[11] A. Carbayo, J.V. Cuevas, G. Garcia-Herbosa, J. Organomet. Chem., 658 (2002) 15.

[12] I.P. Beletskaya, A.N. Kashin, N.B. Karlstedt, A.V. Mitin, A.V. Cheprakov, G.M. Kazankov, J. Organomet. Chem., 622 (2001) 89

[13] S. Iyer, G.M. Kulkarni, C. Ramesh, Tetrahedron, 60 (2004)
2163.

[14] A. D. Ryabov, Synthesis, (1985) 233.

[15] A. D. Ryabov, R. van Eldik, G. Le Borgne, M. Pfeffer, Organometallics, 12 (1993) 1386.

[16] A. C. F. Caires, E. T. Almeida, A. E. Mauro, J. P. Hemerly, S. R. Valentini, Quím. Nova., 22 (1999) 329.

[17] W. A. Herrmann, V. P. W. Böhm, C. P. Reinsinger, J. Organomet. Chem., 576 (1999) 23.

[18] Z. Liu, T. Zhang, M. Shi, Organometallics, 27 (2008) 2668.

[19] T. Weskamp, V.P.W. Bohm, W.A. Herrmann, J. Organomet. Chem., 585 (1999) 348.

[20] V.P.W. Bohm, C.W.K. Gstottmayr, T. Weskamp, W.A. Herrmann, J. Organomet. Chem., 595 (2000) 186.

[21] J.-Y. Li, A.-J. Yu, Y.-J. Wu, Y. Zhu, C.-X. Du, H.-W. Yang, Polyhedron, 26 (2007) 2629.

[22] H. Weissman, D. Milstein, Chem. Commun., 18 (1999) 1901.

[23] R.B. Bedford, C.S.J. Cazin, Chem. Commun., 17 (2001) 1540 .

[24] R.C. Huang, K.H. Shaughnessy, Organometallics, 25 (2006) 4105.

[25] J.L. Zhang, L. Zhao, M.P. Song, T.C.W. Mak, Y.J. Wu, J. Organomet. Chem., 691 (2006) 1301.

[26] J.F. Gong, G.Y. Liu, C.X. Du, Y. Zhu, Y.J. Wu, J. Organomet. Chem., 690 (2005) 3963.

[27] I.J.S. Fairlamb, A.R. Kapdi, A.F. Lee, G. Sanchez, G. Lopez, J.L. Serrano, L. Garcia, J. Perez, E. Perez, Dalton Trans., 23 (2004) 3970 .

[28] D.A. Alonso, C. Nájera, M.C. Pacheco, Org. Lett., 2 (2000) 1823.

[29] G.A. Grasa, A.C. Hillier, S.P. Nolan, Org. Lett., 3 (2001) 1077.

[30] K. Karami, M. Mohamadi, Appl. Organometal. Chem., 24 (2010) 828

[31] K. Karami, C. Rizzoli, M. Mohamadi-Salah, J. Organomet. Chem., 696 (2011) 940.

[32] K. Karami, N. Rahimi, M. Bahrami Shehni, Tetrahedron Lett., 53 (2012) 2428.

[33] A. R. Hajipour, K. Karami, A. Pirisedigh, A. E. Ruoho, J. Organomet. Chem., 694 (2009) 2548.

[34] A. R. Hajipour, K. Karami, A. Pirisedigh, Appl. Organometal. Chem., 23 (2009) 5.

[35] J. Albert, J. Granell, J. Zafrilla, M. Font-Bardia, X. Solans, J. Organomet. Chem., 690 (2005) 422.

[36] C. Tan, F.S. Liu, D.S. Shen, T. Cheng, Z.Z. Zhou, Catal. Lett., 141 (2011) 1332.

[37] A. Sud, R.M. Deshpande, R.V. Chaudhari, Catal Commun, 8 (2007) 183. 